\title{
Condições de trabalho e saúde de motoristas de transporte coletivo urbano
}

\author{
Márcia Battiston \\ Centro Universitário Barriga Verde \\ Roberto Moraes Cruz \\ Universidade Federal de Santa Catarina \\ Maria Helena Hoffmann \\ Universidade do Vale do Itajaí
}

\begin{abstract}
Resumo
O objetivo do presente estudo foi caracterizar as condições de trabalho e saúde de motoristas de transporte coletivo urbano da cidade de Florianópolis, Santa Catarina, tendo como suporte principal as contribuições oriundas da Psicologia Ambiental, da Psicologia do Trabalho e da Ergonomia. Foram realizadas observações do local de trabalho, das linhas e do comportamento do motorista durante o percurso na linha. Foram entrevistados 21 motoristas e as falas serviram de recurso para a análise qualitativa organizada em categorias analíticas. Pôde-se concluir que a atividade de dirigir é desgastante, causa fadiga e sua eficácia está relacionada principalmente a fatores ambientais do local de trabalho e a forma como os motoristas lidam com esses fatores. Há a incidência de distúrbios orgânicos (dores na cabeça, nas pernas e problemas auditivos) e psíquicos (como estresse, irritabilidade e fadiga), que afetam não só a atividade de dirigir mas também a vida social e coletiva desse profissional.
\end{abstract}

Palavras-chave: motoristas; condições de trabalho; saúde do trabalhador; psicologia do trabalho

\begin{abstract}
Work and health conditions of urban public bus drivers. The purpose of this study was to characterize work and health conditions of urban bus drivers of Florianópolis, Brazil, using as principal support the contributions derived from Environmental Psychology, Working Psychology and Ergonomics. Observations were made at work site, routes and of driver's behavior throughout the route. Twenty-one drivers were interviewed and the lines were used as a resource for the qualitative analysis organized in analytical categories. It was concluded that the driving activity is consuming, causes fatigue and its efficacy is mainly related to environmental factors from the work site and the way the drivers deal with it. Organic (head soreness, leg soreness and hearing problems) and psychic (as stress, irritability and fatigue) disturbs affect not only the driving activity but also the social and community life of this professional.
\end{abstract}

Keywords: drivers; work conditions; worker’s health; work psychology

A s condições de saúde e de trabalho de motoristas de transporte coletivo urbano podem ser consideradas um importante fator de dimensionamento da qualidade de vida dos centros urbanos, visto que diferentes fatores ambientais e de interação social contribuem para o aumento do estresse, dentre eles o trânsito. Segundo a Associação Nacional de Empresas de Transportes Urbanos (NTU, 1999), o caos do trânsito nas cidades de médio e grande porte - e já chegando às de menor porte - é um fator de grande influência no estresse das pessoas residentes, principalmente, em áreas urbanas.

O trabalho do motorista de transporte coletivo urbano está diretamente relacionado ao ambiente no qual o mesmo é reali- zado. Diferente das pessoas que desempenham suas atividades profissionais em ambientes fechados como salas ou lojas, algumas vezes climatizados e relativamente confortáveis, esse profissional desempenha suas atividades num ambiente público, o trânsito. Não possui, portanto, um local restrito e bem definido para realizar suas tarefas; ao contrário, trabalha fora dos portões da empresa, estando sujeito a intempéries como o clima, as condições de tráfego e do trajeto das vias.

A condição de trabalho interfere no estado psicofisiológico do motorista, traduzindo-se em irritabilidade (que pode levar a um comportamento agressivo na direção), insônia (podendo resultar em sonolência nas horas de traba- 
lho, diminuindo os reflexos) e, em especial, distúrbios na atenção (fator essencial para a direção segura).

O estudo ora apresentado partiu da necessidade de realizar uma investigação no campo da Psicologia, que possibilite caracterizar as condições de trabalho e de saúde dos motoristas de transporte coletivo urbano por ônibus. Os objetivos desse estudo compreendem, dessa forma, a caracterização das condições de trabalho a que estão submetidos os motoristas de ônibus da cidade de Florianópolis, bem como a identificação da sua percepção sobre o trabalho que realizam.

\section{Análise da atividade de transportar pessoas}

As pessoas utilizam as vias públicas para passeio ou para se deslocarem deliberadamente (levar os filhos à escola, ir e vir de seus locais de trabalho, etc.), além das que as utilizam como meio de exercer o seu trabalho. Entre os profissionais que atuam no trânsito, destacam-se os motoristas de transporte coletivo urbano. O trabalho destes profissionais consiste em fazer contínuos deslocamentos ("transportamentos") levando e trazendo pessoas aos destinos predeterminados. Possui um "macro" local de trabalho que é o trânsito, e um "micro", que é o ônibus. Por esta peculiar característica nenhum outro profissional sofre tanto as pressões do ambiente viário quanto os motoristas.

Hoffmann (2000) afirma que estas pressões têm origens externas e internas. Por pressões externas destacam-se as exigências do trânsito (ambiente), o respeito ao sistema convencional de normas (código), os limites de seu trabalho como, por exemplo, nível do tráfego, semáforos, congestionamentos, acidentes, além de condições adversas como o clima e o estado de conservação da pista. Por pressões internas destacam-se as condições ergonômicas do veículo: posição do motor, precariedade mecânica, além do ruído e das vibrações.

Os motoristas de ônibus estão submetidos às normas da empresa para a qual trabalham de forma peculiar, pois permanecem a maior parte da jornada de trabalho fora dos limites convencionais de uma empresa. Esse aspecto geralmente implica em atribuição de normas rígidas de fiscalização no que diz respeito ao cumprimento de horários (independente das pressões externas e internas), cuidados com o veículo (dado que são responsáveis por qualquer dano ao mesmo), diversidade dos comportamentos dos passageiros (pressão interna), além da responsabilidade que têm sobre a vida das pessoas que conduzem durante horas diárias.

O conhecimento das condições de saúde e de trabalho e as possíveis mudanças podem trazer como principal conseqüência a reestruturação do trabalho de motorista, implicando diretamente nas condições de trabalho a que está submetido este profissional. Mas afinal, como "andam" as condições de trabalho e saúde dos motoristas de ônibus?

\section{Contribuições da Psicologia Ambiental}

A situação de trabalho pode ser entendida como o meio (ambiente) no qual um indivíduo desempenha sua tarefa (trabalho) e a forma (atividade) como ele a executa. Engloba tudo que diz respeito ao cumprimento dos objetivos do trabalho e execução das atividades. Estas situações podem influenciar em aspectos do trabalho que dizem respeito ao motorista, como a satisfação e a penosidade decorrentes do processo de trabalho. Para melhor entendimento do que seja o "ambiente”, utilizar-se-ão os aportes da Psicologia Ambiental.

A Psicologia Ambiental é uma subárea da Psicologia que vem se desenvolvendo nos últimos 30 anos. Seu foco de atenção é o estudo das relações entre o homem e seu ambiente, um sistema de interações sociais, culturais ou físicas que influenciam na atividade humana (Stokols \& Altman, 1987). De maneira ampla, a Psicologia Ambiental estuda o inter-relacionamento entre o comportamento e o ambiente, analisando essa relação no contexto em que ocorre. Há ênfase na reciprocidade, pois o comportamento é tão afetado pelo ambiente quanto o ambiente é afetado pelo comportamento.

Os diferentes aspectos que podem estar presentes no ambiente de trabalho, influenciando na satisfação, no desempenho e na saúde do indivíduo são descritos por Sundstrom, Bell, Busby e Asmus (1996) e podem ser observados na Tabela 1.

Tabela 1

Relação entre níveis de análise, aspectos do ambiente físico, processos envolvidos e resultados (com base em Sundstrom et al., 1996)

\begin{tabular}{|c|c|c|c|}
\hline Níveis de análise & Aspectos do ambiente físico & Processos envolvidos & Resultados \\
\hline Individual & $\begin{array}{l}\text { Condições do ambiente: temperatura, qualidade do ar, } \\
\text { iluminação, barulho, música. } \\
\text { Espaço de trabalho: cor, equipamentos, cadeiras, } \\
\text { espaço disponível. } \\
\text { Instalações de apoio: corredores, banheiros, elevador. }\end{array}$ & $\begin{array}{l}\text { Adaptação } \\
\text { Arousal } \\
\text { Sobrecarga } \\
\text { Estresse } \\
\text { Fadiga } \\
\text { Atitudes }\end{array}$ & $\begin{array}{l}\text { Satisfação } \\
\text { Performance }\end{array}$ \\
\hline Interpessoal & $\begin{array}{l}\text { Espaços de trabalho: diferenciação } \\
\text { Layout de salas: móveis e sua disposição } \\
\text { Layout de ambientes construídos: proximidade no } \\
\text { espaço de trabalho, enclosure do espaço de } \\
\text { trabalho, ambientes pra reunião. }\end{array}$ & $\begin{array}{l}\text { Identidade } \\
\text { Status } \\
\text { Regulação de emergência } \\
\text { Apresentação } \\
\text { Escolhas na comunicação }\end{array}$ & $\begin{array}{l}\text { Comunicação adequada } \\
\text { Formação e coesão de grupo }\end{array}$ \\
\hline Organizacional & $\begin{array}{l}\text { Ambientes construídos: separação e diferenciação de } \\
\text { unidades de trabalho }\end{array}$ & $\begin{array}{l}\text { Congruência entre a estrutura } \\
\quad \text { organizacional e o ambiente físico }\end{array}$ & Eficácia organizacional \\
\hline
\end{tabular}


Além desses aspectos da situação de trabalho observados por Sundstrom et al. (1996), Seligmann-Silva (1995) destaca que diferentes situações de trabalho produzem diferentes efeitos psicológicos no trabalhador, como tensão, fadiga, medo e tristeza. "Assim, por exemplo, o entendimento das relações entre as características das tarefas e os tempos exigidos para o cumprimento das mesmas permite compreender a gênese de tensões e desgaste mental” (Seligmann-Silva, 1995, p. 290). Afirma, ainda, que a organização e as condições de trabalho são fatores que devem ser levados em consideração na avaliação dos processos de saúde mental em contextos laborais.

\section{Contribuições da Psicologia do Trabalho e da Ergonomia}

A Psicologia do Trabalho e a Ergonomia se situam como disciplinas científicas de um mesmo campo de estudos: o trabalho humano. Em torno deste campo se constrói um modus operandi que cria vínculos metodológicos importantes sobre a análise do trabalho, subsidiados pelas diversas perspectivas teóricas geradas pelas interfaces entre as ciências humanas e as ciências aplicadas (Cruz, Alchieri, \& Sardá, 2002).

A necessidade de explicar as condutas dos indivíduos sob diferentes condições de trabalho criou a possibilidade de estruturar modelos de investigação dos processos psicológicos subjacentes à natureza da atividade de trabalho e às suas conseqüências. O campo de estudos denominado de Psicologia do Trabalho foi construído, historicamente, a partir de uma série de situações práticas da atividade do trabalho, calcadas em certo formalismo científico, por meio das teorias e técnicas de intervenção (Cruz, 2001).

A Ergonomia é considerada uma ciência do trabalho que atua especificamente na investigação das condições de conforto, segurança, eficiência e saúde no trabalho. A abordagem é multidisciplinar, exigindo conhecimento do trabalho (tarefa), do trabalhador (usuário) e da organização (ambiente sócio-técnico). Para Wisner (1987), a ergonomia constitui o conjunto de conhecimentos científicos relativo ao ser humano necessário à concepção de ferramentas, máquinas e dispositivos que possam ser utilizados com o máximo de conforto, segurança e eficácia.

Esses aspectos são estudados a partir da Análise Ergonômica do Trabalho que, segundo as características fundamentais da tarefa, pretende elucidar seus efeitos sobre a saúde do trabalhador e os resultados do seu trabalho. Analisando as características do local de trabalho que podem produzir estresse psicológico, Smith (1987) e Cooper e Marshall (1976) apontam aspectos como: a carga de trabalho inadequada, o ambiente hostil, a ambigüidade de funções, a falta de tarefas estimulantes, a sobrecarga cognitiva, o relacionamento conflituoso com supervisores ou com outros companheiros de trabalho, a falta de controle sobre as tarefas ou sobre a tomada de decisões e a falta de apoio social por parte de supervisores, companheiros de trabalho ou familiares.

O ambiente de trabalho que pode gerar estresse psicológico traz também riscos à saúde física dos trabalhadores.
Revisão da literatura realizada por Winkleby, Ragland, Fisher e Syme (1988), sobre os riscos a saúde a que estão expostos os motoristas de ônibus, destacou como principais causas de mortalidade e morbidade três grupos de doenças: doenças cardiovasculares, do aparelho gastrointestinal e problemas musculoesqueléticos. Outros estudos apontam para a mesma direção, considerando a profissão de motorista de ônibus como tendo maior risco de desenvolver doenças cardíacas e musculoesqueléticas (Netterstrom et al.,1988; Netterstrom \& Juel, 1988; Paradis et al., 1989).

Na atividade de motorista, destacam-se como importantes aspectos a serem analisados quando do estudo das condições de trabalho: a carga de trabalho, o posto de trabalho, o ruído e as vibrações, a temperatura, as posturas forçadas e os movimentos repetitivos de membro superior.

Carga de trabalho. Entende-se por carga de trabalho o produto da relação entre as exigências do trabalho e a capacidade de desempenho e de enfrentamento do trabalhador. Sob condições aversivas, essas exigências tendem a gerar sobrecargas sobre os sistemas físico e psicológico. Essas sobrecargas podem manifestar-se, por exemplo, como dores ou tendinites (aspecto físico) ou como desatenção ou irritabilidade (aspecto psicológico). Segundo Frankenhaeuser (2001), é preciso ainda distinguir a carga de trabalho quantitativa da qualitativa. A primeira está relacionada à quantidade excessiva de trabalho que deve ser executado em um tempo determinado, e a segunda a tarefas repetitivas que precisam de variedade e dificuldade.

Posto de trabalho. O posto de trabalho refere-se ao desenho do local e a uma série de equipamentos dispostos neste ambiente que podem ser observados objetivamente (Stokols, 2001). As características do posto de trabalho podem influenciar no bem-estar e no conforto do trabalhador. Segundo Millies (2001), o posto de trabalho do motorista de ônibus, apesar do tamanho do veículo, resume-se a pouco mais de $1,5 \mathrm{~m}^{2}$. Nesse local estão dispostos os instrumentos necessários à realização da tarefa de conduzir pessoas. Segundo o autor, na década de 1990, foi realizada uma ampla investigação no Canadá, Suécia, Alemanha e Países Baixos, sobre os aspectos ergonômicos do posto de trabalho e de outros aspectos dos ônibus. Essa investigação resultou em uma série de modificações no posto de trabalho, como mudanças no ajuste do assento e do volante, levando em consideração a altura e características especiais como o sobrepeso e o comprimento de braços e pernas. Ainda como resultado desta investigação, os ajustes do assento e do volante devem ser coordenados, de modo que os profissionais encontrem posições cômodas e ergonomicamente saudáveis. O painel de controle foi otimizando, facilitando o acesso aos comandos e à visibilidade dos instrumentos.

Ruído. Segundo um estudo realizado pela Comissão de Saúde Pública da Espanha (2000), o ruído é um som inarticulado e confuso, mais ou menos forte. Para Suter (2001), o ruído é um dos fatores de risco laborais mais comuns, sendo os níveis de ruído perigosos à saúde facilmente identificáveis. Sendo assim, na maioria dos casos é tecnica- 
mente viável controlar o excesso de ruído aplicando a tecnologia existente. Contudo, nota-se a ausência de programas preventivos, o que, para o autor, deve-se ao fato de que o ruído é normalmente aceito como um "mal necessário" e, embora seja capaz de provocar danos à saúde não é, literalmente, visível, não traz ferimento e, quando o trabalhador é capaz de suportar as primeiras semanas de trabalho exposto ao ruído, tem a sensação de haver-se “acostumado”.

Segundo Ferreira e Pinto (1998), a cronicidade dos efeitos do ruído (são necessários vários anos para induzir a surdez) e a dificuldade de estabelecer correlações diretas com outras doenças (hipertensão, estresse, aumento do número de acidentes) fazem do ruído um agente reconhecível, mas com repercussões “pouco visíveis”. Para Cavalcanti (1996), a localização do motor expõe os motoristas a risco potencial de surdez ocupacional, pois o ruído do motor em decibéis é superior ao limite para tal risco. Estudo realizado por Cordeiro, Lima-Filho e Nascimento (1994) com motoristas e cobradores de ônibus urbano, usuários de um sistema de saúde ocupacional da cidade de Campinas, detectou a associação da perda auditiva induzida pelo ruído com o tempo acumulado de trabalho. Houve ainda associação com o fator idade.

Vibrações. As vibrações são movimentos oscilatórios. Segundo Griffin (2001), elas podem ser de corpo inteiro ou transmitidas pelas mãos. As vibrações de corpo inteiro ocorrem quando o corpo está apoiado em uma superfície vibrante (por exemplo, quando está sentado em um assento que vibra, pisando ou deitado sobre uma superfície vibrante). Para o autor esse tipo de vibração se faz presente em todas as formas de transporte e no trabalho com maquinaria industrial. As vibrações transmitidas pelas mãos se fazem presentes em diversos processos industriais, na agricultura, na mineração e na construção. Silva e Mendes (2005) estudaram a vibração de corpo inteiro a que está exposto o motorista e concluíram que os valores revelam situação de risco, pois superam em muito o limite estabelecido pela ISSO2631 para oito horas diárias.

Temperatura. A temperatura é outro aspecto que pode interferir na atividade dos motoristas, podendo alterar seu estado emocional. Segundo o DETRAN do estado de Pernambuco (s/d), o motorista de ônibus deve estar a $27^{\circ} \mathrm{C}$ para encontrar-se em uma situação de bem-estar; mas, no verão, a temperatura dentro de um veículo lotado chega a $50^{\circ} \mathrm{C}$. Essa alta temperatura pode causar desconforto (deixando o motorista inquieto), alteração de humor (irritabilidade e agressividade) e interferir no desempenho do motorista ao executar sua tarefa de dirigir (desatenção e sonolência). Nielsen (2001) destaca fatores como a velocidade e a umidade do ar como determinantes no trabalho em ambientes quentes. Em ambientes fechados, a qualidade da ventilação e sua eficácia também determinam o nível de estresse provocado pelo calor.

Posturas forçadas. Segundo a Comissão de Saúde Pública da Espanha (2000), as posturas forçadas compreendem "as posições fixas ou restritivas do corpo, as posturas que sobrecarregam os músculos e tendões, as posturas que car- regam as articulações de uma maneira assimétrica e as posturas que produzem carga estática na musculatura” (p. 12). As tarefas que requerem posturas forçadas implicam fundamentalmente o tronco, os braços e as pernas e sua principal conseqüência são os transtornos musculoesqueléticos. Devido ao lento aparecimento dos transtornos e sua aparência inofensiva, são, muitas vezes, subestimados até que o sintoma seja crônico e o dano permanente.

Movimentos repetitivos de membro superior. Entendese por movimento repetitivo um grupo de movimentos contínuos, mantidos durante o trabalho, que implicam um conjunto osteomuscular provocando neste mesmo conjunto fadiga muscular, sobrecarga, dor ou lesão (Comissão de Saúde Pública da Espanha, 2000). A carga de trabalho tanto estática quanto dinâmica, junto a fatores psicológicos e orgânicos do próprio trabalhador, além de um ambiente desagradável e pouco gratificante se somam para a formação da fadiga muscular. Conforme sua cronicidade, aparecem as contraturas, a dor e a lesão, formando um ciclo vicioso de dor. Os diagnósticos são muito variados: tendinite, peritendinite, tenosinovite, mialgias, dentre outros.

\section{Método}

A presente pesquisa compreende uma abordagem descritiva e exploratória dado que buscou correlacionar fatos ou fenômenos sem manipulá-los, com a finalidade de obter nova percepção e descobrir novas idéias ou relações existentes entre os elementos saúde e trabalho do motorista de transporte coletivo urbano.

\section{Participantes}

Participaram desta pesquisa 21 motoristas de ônibus da cidade de Florianópolis, SC. O transporte coletivo nesta cidade é administrado pelo Núcleo de Transportes da Prefeitura Municipal, responsável pela fiscalização e gerenciamento dos transportes urbanos. A escolha dos participantes teve por critérios as condições de acessibilidade aos indivíduos e às linhas de ônibus.

A distribuição dos participantes nas faixas etárias é de 47,6\% para motoristas de 25 a 40 anos e de $52,4 \%$ para os de 41 a 56 anos. Nesta variável, obteve-se uma média de 41,2 anos e um desvio padrão de 8,4. Todos são casados e apenas 3 participantes não relatam morar em casa própria. As famílias são constituídas de pelo menos mais um membro que auxilia na renda doméstica, o que certamente contribui para lhes assegurar as condições básicas de sobrevivência, já que pouco mais da metade possui pelo menos dois filhos (57 \%). Com relação ao grau de escolaridade dos motoristas 85,7\% têm apenas o ensino fundamental.

\section{Instrumentos}

Os instrumentos utilizados para a coleta dos dados foram a entrevista e a observação estruturada. Ambas contaram com um roteiro previamente estabelecido buscando abranger os pontos necessários para a obtenção de dados que 
respondessem aos objetivos da pesquisa. Dessa forma os instrumentos foram utilizados para: (a) a observação dos terminais para sua descrição e caracterização ${ }^{1}$; (b) a observação das condições das tarefas do motorista no transporte de pessoas, no itinerário de 21 linhas de ônibus; e (c) as entrevistas realizadas com 21 motoristas, com o objetivo de identificar os possíveis agentes considerados estressores no local de trabalho (tanto o micro quanto o macro-ambiente), além de descrever a percepção dos motoristas em relação as suas condições de trabalho.

\section{Procedimentos}

Para a obtenção dos dados procedeu-se da seguinte forma:

(a) a observação dos terminais foi realizada utilizandose um roteiro, por meio do qual caracterizou-se o local de trabalho dos motoristas quanto ao conforto oferecido, locais de alimentação, sanitários, local de descanso e/ou parada entre as viagens. Os dados foram analisados e categorizados e uma caracterização geral do local de trabalho foi configurada;

(b) para a observação das linhas, durante o cumprimento do itinerário, utilizou-se um roteiro de observação do trajeto da viagem, que permitiu conhecer in loco as condições de trabalho desses profissionais, desde a intensidade do tráfego até a conservação da pista, bem como a relação desses fatores com o comportamento observável do motorista; e

(c) as entrevistas foram realizadas nos terminais urbanos, no estacionamento dos ônibus e no ponto final das linhas por meio de um roteiro previamente estruturado. As falas dos entrevistados, juntamente com as observações, foram os principais recursos para a análise da situação de trabalho dos motoristas.

\section{Organização e tratamento dos dados}

A organização dos dados foi estruturada tomando-se por base os elementos de análise propostos por Sundstrom e colaboradores (1996) e apresentados na Tabela 1, para as situações de trabalho. Além dos elementos que propõem os autores, outros itens foram acrescentados a partir da revisão da literatura sobre o assunto. Novos conjuntos temáticos foram estabelecidos para cada categoria de acordo com as falas dos participantes. Os passos para a elaboração das categorias analíticas e seus respectivos conjuntos temáticos podem ser mais bem visualizados na Figura 1.

Os passos apresentados na Figura 1 resultaram na organização das categorias e dos conjuntos temáticos apresentados na Tabela 2.

Os dados numéricos foram analisados por meio de tratamento estatístico-descritivo com base nos indicadores da freqüência da ocorrência e percentual. As informações verbais foram sistematizadas em conjuntos temáticos que derivam de categorias estabelecidas a partir dos conteúdos das falas e analisadas com base na literatura, textos, documentos, ações e observações, conforme orientam Luna (1998) e Zanelli (1992).

\section{Resultados e Discussão}

\section{Condições fisiológicas}

As condições fisiológicas dizem respeito a variáveis relacionadas à atividade de dirigir. Podem interferir nessa atividade a qualidade e as horas de sono, as refeições e o uso de medicamentos. A qualidade e a quantidade de sono foram consideradas pelos motoristas suficientes para descansar: $76,2 \%$ afirmam dormir de 7 a 8 horas por dia. Com relação à interferência da jornada de trabalho (turnos) na regulação adequada dos horários de refeição, não parece haver evidências que apontem para qualquer problema em realizá-la em outros horários, visto que $71 \%$ dos entrevistados dizem fazer pelo menos três refeições por dia.

O uso de medicação também constitui um fator que pode interferir na atividade do motorista. Muitos dos medicamentos para dores, por exemplo, podem causar sonolência e deixar mais lentos os reflexos. Cerca de $40 \%$ dos entrevistados afirmaram usar medicação regularmente, e os motivos foram, em geral, as dores, sejam dores de cabeça, dores nas pernas ou nos braços, no pescoço ou na musculatura corporal como um todo.

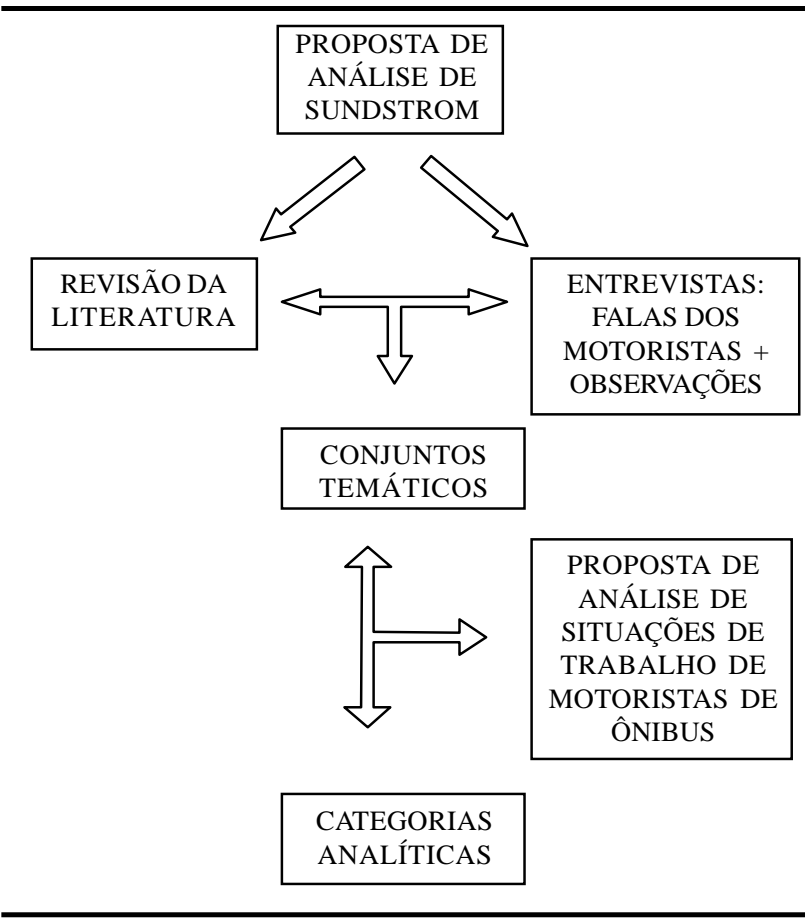

Figura 1. Passos para a elaboração das categorias analíticas e respectivos conjuntos temáticos. 
Tabela 2

Categorias e conjuntos temáticos para o estudo das condições de trabalho de motoristas de ônibus

\begin{tabular}{|c|c|}
\hline Categorias & Conjuntos temáticos \\
\hline Perfil sócio-demográfico & $\begin{array}{l}\text { Idade } \\
\text { Escolaridade } \\
\text { Número de filhos } \\
\text { Casa própria } \\
\text { Membros que contribuem com a renda familiar }\end{array}$ \\
\hline Condições fisiológicas & $\begin{array}{l}\text { Horas de sono } \\
\text { Qualidade do sono } \\
\text { Número de refeições/dia } \\
\text { Uso de medicação }\end{array}$ \\
\hline Condições ambientais internas: a atividade de dirigir e o ônibus & $\begin{array}{l}\text { Posto de trabalho } \\
\text { Paradas para embarque e desembarque de passageiros } \\
\text { Posturas forçadas } \\
\text { Ruído e vibrações } \\
\text { Posição do motor } \\
\text { Condições mecânicas do ônibus } \\
\text { Movimentos repetitivos dos membros superiores } \\
\text { Temperatura } \\
\text { Ventilação } \\
\text { Clima }\end{array}$ \\
\hline Condições ambientais externas: o trânsito & $\begin{array}{l}\text { Engarrafamentos } \\
\text { Outros veículos da via } \\
\text { Conservação da pista } \\
\text { Trânsito como um todo } \\
\text { Condições de trabalho }\end{array}$ \\
\hline Relacionamentos interpessoais no trabalho & $\begin{array}{l}\text { Passageiros } \\
\text { Fiscais } \\
\text { Colegas de trabalho } \\
\text { Outros motoristas da via }\end{array}$ \\
\hline Medos e sofrimento no trabalho & $\begin{array}{l}\text { Medo } \\
\text { Sofrimento }\end{array}$ \\
\hline Organização e controle do processo de trabalho & $\begin{array}{l}\text { Instalações de apoio } \\
\text { Tempo para o cumprimento do itinerário da rota } \\
\text { Intervalos } \\
\text { Formas de pagamento } \\
\text { Controle do processo de trabalho } \\
\text { Comunicação } \\
\text { Formas de controle } \\
\text { Participação da prefeitura } \\
\text { Benefícios }\end{array}$ \\
\hline
\end{tabular}

\section{Condições ambientais internas: ônibus}

O posto de trabalho do motorista é composto por uma série de controles dos quais ele se utiliza a fim de cumprir sua tarefa. A disposição desses equipamentos é igual para todos os motoristas, já que é a indústria automobilística a responsável pelo desenho interno e externo dos ônibus. Os comportamentos envolvidos na atividade de dirigir denotaram o esforço necessário à realização dessa atividade, que está diretamente relacionada aos componentes do posto de trabalho do motorista. É possível inferir uma relação entre a manifestação de dores físicas e as características da cabine, especialmente com o modelo do assento. A falta de conforto do assento foi justificada pelos entrevistados por considerarem o banco duro. O espaço restrito da cabine também foi considerado um fator que causa desconforto e insatisfação. Nesse espaço, há restrição de movimentos, pois o diâmetro do volante é grande e a possibilidade de controle que os motoristas têm para o ajuste dos equipamentos ao seu tipo físico é limitada. Pôde ser observado o uso de acessórios por parte desses profissionais "para tornar o assento mais confortável”, como a colocação de protetores de banco que servem como equipamentos de massagem nas costas.

Salienta-se, ainda, que as linhas com maior número de paradas para embarque e desembarque de passageiros foram as que aparentemente causaram maior fadiga nos motoristas. O número de comportamentos envolvidos na parada e posterior arrancada dos ônibus é elevado, sendo que os mo- 
vimentos físicos envolvidos ocorrem com o motorista sempre na mesma postura, ou seja, sentado. Esta posição pode ser classificada, segundo a Comissão de Saúde Pública da Espanha (2000), como postura forçada, já que restringe a possibilidade de movimentos, sobrecarregando os músculos e tendões especialmente do tronco (pois o motorista está durante toda a jornada de trabalho sentado), dos braços (essenciais para a atividade de dirigir - uso do volante) e das pernas (fundamentais para a movimentação efetiva do ônibus - acelerador, embreagem e freio). Essa Comissão apresenta ainda como principais conseqüências dessas posturas os transtornos musculoesqueléticos.

Outros fatores importantes na atividade do motorista são o ruído e as vibrações a que está exposto durante sua jornada diária de trabalho. Segundo Suter (2001), o fato de não produzir efeitos visíveis e, na maioria dos casos, dor manifesta torna o fator ruído subestimado nos ambientes de trabalho. Os motoristas que se sentiram incomodados com o ruído $(57,1 \%)$ justificaram-no pela localização do motor. Para Cavalcanti (1996), a localização do motor expõe os motoristas a risco potencial de surdez ocupacional, pois o ruído do motor em decibéis é superior ao limite estabelecido para evitar tal risco. Ônibus com motor dianteiro causam maior incômodo já que a origem do ruído está exatamente ao lado do motorista, e ao ruído do motor somam-se o do tráfego e dos próprios passageiros. Os problemas fisiológicos, como dor de cabeça, também podem ser originários do ruído.

O incômodo causado pelo ruído vai além do gerado no ambiente de trabalho. Houve relatos de dificuldade de compreensão da fala das pessoas e a necessidade de ouvir a televisão em volume elevado após o término da jornada de trabalho. Esses são alguns dos sintomas da exposição excessiva ao ruído, podendo ocasionar a perda auditiva, dado que $47,6 \%$ dos motoristas relataram a ocorrência de zumbidos. Houve, ainda, relatos de motoristas que sonham com o barulho do motor. Tal resultado corrobora a pesquisa de Cordeiro, Lima-Filho e Nascimento (1994), que detectaram a associação da perda auditiva induzida pelo ruído com o tempo acumulado de trabalho em estudo realizado com motoristas e cobradores de ônibus.

As condições mecânicas também podem agravar a intensidade do ruído. As empresas são as responsáveis pela manutenção dos veículos. A prefeitura fiscaliza as condições mecânicas por meio de vistorias periódicas. Todos os motoristas classificaram como boas as condições mecânicas do veículo que dirigem e acrescentaram que sempre que solicitam à empresa algum tipo de reparo, ele é realizado.

Além das condições mecânicas, o estado de conservação da pista também pode causar a vibração do ônibus, especialmente do espaço do motorista. O ruído do motor foi constante durante todo o trajeto; intensificou-se na subida de morros íngremes onde ocorre maior aceleração e a exigência do motor é maior. Nesses momentos, intensificou-se também a vibração sentida no corpo inteiro. $\mathrm{O}$ alto índice de dor apontado pelos motoristas, tanto na coluna e nas pernas $(76,2 \%)$ quanto na cabeça e no pescoço (81\%), repre- senta claramente a fadiga resultante da atividade desempenhada por estes profissionais.

Os movimentos repetitivos dos membros superiores, incluindo os braços, são característicos da atividade. Segundo a Comissão de Saúde Pública da Espanha (2000), movimentos repetitivos é um grupo de movimentos contínuos que, mantidos durante a jornada de trabalho, implicam em fadiga muscular, sobrecarga, dor ou lesão. A carga de trabalho associada a fatores psicológicos e orgânicos do próprio trabalhador, ambiente desagradável e pouco gratificante contribui para a formação da fadiga muscular. Conforme sua cronicidade, aparecem as contraturas, a dor e a lesão. Esse tipo de lesão ocorre, geralmente, na região do ombro e dos braços, do punho e das mãos. O fato de o motorista estar constantemente trocando de marchas e efetivamente com os braços esticados para frente, sem apoio, em posição desconfortável, vem ratificar a possibilidade da ocorrência de lesão.

Outra condição ambiental que interfere no trabalho do motorista é a temperatura e a ventilação internas do ônibus. Pôde-se observar que o motor localizado ao lado do assento do motorista, na maioria dos ônibus, eleva a temperatura interna do posto de trabalho e o número de passageiros dificulta a ventilação, aumentando a sensação de calor. Segundo o DETRAN do estado de Pernambuco (s/d), a temperatura dentro de um ônibus lotado, no verão, pode chegar a $50^{\circ} \mathrm{C}$, o que pode ocorrer em outros estados com médias de temperatura anual semelhantes. Embora no presente estudo não tenha sido realizada medição da temperatura interna nos veículos, houve relatos dos entrevistados quanto aos efeitos que podem ter como causa o calor no interior no veículo, agravado pelo emanado do motor (quando dianteiro), como a perda dos pêlos na área da canela e panturrilha da perna que fica ao lado do motor.

Junto a essas variáveis - altas temperaturas e baixa ventilação - os dias de chuva aparecem como fatores que interferem na atividade de dirigir. É a influência do clima no cumprimento da tarefa do motorista. Além do aumento no número de veículos circulando em dias de chuva, há o fator do asfalto molhado, conseqüentemente a aderência dos pneus na pista diminui, aumentando a probabilidade da ocorrência de acidentes. A visibilidade também é prejudicada, requerendo maior atenção por parte dos motoristas, pois, segundo eles, pode ocorrer o embaçamento dos vidros, dificultando a visibilidade.

\section{Condições ambientais externas: trânsito}

Os engarrafamentos e os outros veículos da via foram os aspectos que causaram maior irritação aparente nos motoristas durante as observações. $\mathrm{O}$ tempo perdido nos engarrafamentos era logo compensado com altas velocidades nos trechos em que isso era possível ou no final das linhas. Para Tapia-Granados (1998), o planejamento urbano e o sistema viário como um todo não acompanharam o aumento mundial da frota de veículos, o que traz como conseqüências os congestionamentos, os ruídos e a emissão de poluentes. O autor aponta ainda os transportes coletivos e as bicicletas como meios de transporte que podem contribuir para a diminuição 
dos engarrafamentos, bem como do ruído e da emissão de gases tóxicos pelos motores dos carros.

A conservação da pista é outro aspecto que pode dificultar a atividade de dirigir e o cumprimento da tarefa. Em geral a conservação das pistas pôde ser classificada como razoável, oscilando de pistas bem conservadas a pistas pessimamente conservadas. Foram consideradas "linhas boas" pelos motoristas aquelas em que os passageiros são "mais educados”, e "ruins” aquelas onde os passageiros são "barra pesada”.

\section{Relacionamento interpessoal no trabalho}

Os relacionamentos dos motoristas de ônibus no trabalho acontecem com os passageiros, os fiscais, os cobradores e outros motoristas. Com relação aos passageiros, a observação realizada tanto no interior dos ônibus quanto nos terminais de embarque e desembarque, apontou para um bom relacionamento. No entanto, algumas falas sugeriram a existência de dificuldades: "nós somos só empregados, às vezes temos que relevar [o que falam os passageiros]"; "tem passageiro que reclama do motorista, como se a culpa de ter engarrafamento ou de alguém ter freado na nossa frente fosse nossa”. Essas dificuldades de relacionamento, também foram detectadas em estudo realizado por Paes-Machado e Levenstein (2002) e são agravadas pela insatisfação dos usuários quanto ao serviço ofertado, seja no descompasso entre oferta e demanda - podendo gerar a superlotação do ônibus - seja no tempo de espera em locais sem abrigo ou no tempo perdido em engarrafamentos. Segundo os autores, essa insatisfação traduz-se em conduta agressiva, gerando conflitos no interior do ônibus, entre os próprios passageiros e desses com os rodoviários.

Se com os passageiros, que são a razão de existir do transporte coletivo, a relação é instável, o mesmo acontece quando o assunto são os fiscais. O que se destaca é o reconhecimento conferido pelos motoristas ao poder desses profissionais e a conseqüente frustração pela impossibilidade de controle de sua própria atividade de trabalho. Sato (1995) destaca que o fato de não ter poder sobre o trabalho obriga o trabalhador a submeter-se a situações complicadas como, por exemplo, ser fiscalizado e vigiado constantemente, bem de perto, por passageiros, fiscais e outros motoristas.

A relação dos motoristas com os colegas de trabalho, tanto cobradores quanto outros motoristas, é amistosa. Compartilham as mesmas condições de trabalho e se solidarizam com os colegas.

As relações que estabelecem com outros veículos e, portanto, com outros motoristas, podem ser analisadas em termos de trânsito. Os motoristas têm que circular em vias que são públicas e compartilhar esse espaço com pessoas de visão, opinião e objetivos diferentes dos seus. Ter de exercer atividade regrada em um local onde outras pessoas exercem a liberdade de movimentar-se deliberadamente, pode ser um fator que influencia negativamente o comportamento do motorista no trânsito. Quando houve disputa pelo espaço no trânsito, pôde-se observar comportamentos como frenagens bruscas, "cortar" a frente de outros motoristas e ultrapassagens arriscadas, tanto dos motoristas de ônibus quanto de outros veículos da via. Esse tipo de comportamento ocasionava o desconforto entre os passageiros e a irritação do motorista do ônibus.

A atividade desse profissional é essencialmente solitária. Não compartilha com ninguém as decisões que tem de tomar para executar sua tarefa com segurança. Assume também a responsabilidade pelas vidas que transporta e pela sua própria, o que pode ser elucidado pela fala de um motorista entrevistado: “A gente tá sujeito a qualquer coisa nessa vida, seja no trabalho, seja no dia-a-dia da gente. [...] sabendo das minhas responsabilidades, que a gente trabalha com vidas, a responsabilidade é muito grande”.

\section{Medo e sofrimento no trabalho}

O medo é uma característica natural do ser humano para a sua própria proteção e para que possa adotar estratégias de defesa contra constrangimentos físicos e psicológicos. Negar o medo é tentar esconder por algum motivo ou a causa desse medo ou a sua conseqüência. Os medos apontados pelos motoristas entrevistados podem enunciar uma causa subjacente não só à sua profissão, mas a outras profissões que sofrem as mesmas pressões do mercado de trabalho e das políticas públicas. Os medos apontados pela quase totalidade dos motoristas entrevistados foram o medo de ser assaltado e o de perder o emprego. Um aspecto específico da profissão foi o medo de sofrer um acidente.

Estudo realizado por Costa, Koyama, Minuci e Fischer (2003) nas cidades de Belo Horizonte e São Paulo sobre as condições de trabalhos dos motoristas de passageiros dessas cidades, indica que o medo de sofrer um acidente aumenta em $71 \%$ a chance de estresse com relação aos motoristas que não têm essa preocupação. $\mathrm{O}$ estudo aponta também o medo de ser assaltado (78\% dos entrevistados paulistas e 81,8\% dos motoristas de Belo Horizonte) como um dos principais medos desses profissionais. Belkic e Schnall (1998) apontam para a mesma direção em um estudo realizado com operadores de transporte coletivo da cidade americana de São Francisco, que conclui que o principal estressor desses profissionais é a violência. Outro aspecto do estudo realizado por Costa et al (2003), que verifica-se semelhante, é o medo de perder o emprego, sendo que pouco mais da metade dos entrevistados de ambos os municípios declararam isso. O estudo faz associações entre o medo de ser assaltado e problemas gastrointestinais, e o medo de acidentes e problemas do sono e estresse.

$\mathrm{O}$ medo de perder o emprego pode ser um aspecto que faz com que os motoristas neguem o próprio sofrimento. Estar sofrendo pressão constantemente, seja da empresa ou de outras formas de fiscalização, seja dos passageiros ou das intempéries que o trânsito oferece no dia-a-dia de seu trabalho, faz com que essa atividade receba sobrecargas com as quais os motoristas não sabem lidar.

De acordo com Dejours (1992), a organização do trabalho que anula os comportamentos livres e criativos empobre- 
ce a atividade mental e expõe o corpo a conversões somáticas e a sofrimento psíquico. Esses decorrem da ausência de proteção do aparelho mental que media as necessidades internas e as exigências do meio.

As estratégias individuais de defesa no trabalho perigoso servem para neutralizar o medo, enquanto que em outras situações servem para tornar suportável o trabalho tedioso. Dejours (1992) observa que as estratégias coletivas de defesa funcionam inteiramente desvinculadas de qualquer perspectiva libertadora e respondem unicamente à necessidade de suportar a penosidade do trabalho e, acima de tudo, o medo e a ansiedade. Essas estratégias coletivas defensivas estão voltadas para a negação coletiva dos riscos, favorecendo a continuidade da dominação e a exploração.

\section{Organização e controle do processo de trabalho}

As instalações de apoio existentes até 2003 não eram adequadas. Os terminais tinham poucos sanitários, as condições de higiene eram precárias e havia a proximidade de bares, que favoreciam o consumo de bebidas alcoólicas pelos motoristas. Atualmente os terminais têm melhores condições de higiene, há sanitários e locais de alimentação mais adequados.

Outro fator da organização do trabalho é o tempo para o cumprimento da rota de cada linha, que é predeterminado. O não cumprimento implica em deslocar outro ônibus para que o mesmo cumpra o horário de saída estabelecido para aquela linha. Cumprir, ou não, o horário estabelecido não depende apenas do motorista; depende, essencialmente, das condições de tráfego, ou seja, fluxo de veículos, condições do clima, horário, etc. O tempo da rota também interfere nos intervalos.

Mesmo os motoristas que afirmam não ter intervalo entre as viagens $(9,6 \%)$, em outro momento dizem que esse intervalo fica em torno de cinco minutos. Além do intervalo entre as viagens, os motoristas têm um intervalo determinado que pode variar entre 30 minutos e 1 hora e 30 minutos, dependendo da linha, do horário de trabalho e da situação do trânsito. Nesses intervalos os motoristas costumam fazer suas refeições ou lanches e descansar. Paes-Machado e Levenstein (2002) realizaram estudo sobre a violência, a insegurança e as condições de trabalho de motoristas de transporte coletivo na cidade de Salvador, BA, e detectaram que os intervalos entre as viagens são julgados insuficientes pelos participantes da pesquisa, o que é agravado pelos atrasos nos percursos. Além disso, faltam locais apropriados para os motoristas permanecerem durante esse intervalo, fazendo com que os mesmos se utilizem das instalações de bares, ainda que contra as regras da empresa.

O controle do processo de trabalho é praticamente nulo. A participação nas decisões da empresa é apontada como tarefa do sindicato, embora os motoristas pouco se engajem em lutas pela melhoria da qualidade de seu trabalho. A comunicação é falha tanto no que diz respeito às inovações e mudanças organizacionais e institucionais quanto a projetos e lutas do próprio sindicato.
Há, entretanto, formas de controle por parte da empresa: os descontos feitos no salário sobre avarias nos ônibus. Qualquer que seja o problema - multas por infrações de trânsito, acidentes com danos ao veículo, rodas danificadas no meio-fio - se considerados culpados, os motoristas arcam com as despesas de reparo, sendo este valor descontado na folha de pagamento. Acrescentam-se à análise também os benefícios oferecidos aos motoristas pelas empresas, que se assemelham. Algumas oferecem premiações e festas no final do ano, outras premiações ou convênios médicos. O sindicato da categoria oferece ainda convênio odontológico e na sua sede atende a motoristas e lhes oferece esclarecimentos.

A participação da prefeitura está na fiscalização e na organização do transporte urbano. Além da verificação das condições mecânicas dos ônibus, o Núcleo de Transportes da Prefeitura também é responsável pelo planejamento do sistema de transporte.

\section{Conclusão}

A atividade de dirigir é desgastante, causa fadiga e sua eficácia está relacionada principalmente a fatores ambientais do local de trabalho e à forma como os motoristas desenvolvem estratégias de enfrentamento para lidar com estes fatores. As condições de trabalho e de saúde dos motoristas de transporte coletivo urbano podem ser consideradas fontes dos distúrbios orgânicos ou psíquicos que acometem esses profissionais.

Aspectos como as instalações de apoio (terminais, sanitários, etc.) e o trânsito como um todo (engarrafamentos, outros veículos da via, clima, etc.) são fontes constantes de estresse. Outros aspectos do posto de trabalho, que incluem a disposição dos equipamentos, assento, câmbio de marchas, volante e posição do motor, são fundamentais para a incidência de problemas orgânicos como dores no corpo e problemas auditivos.

O trânsito, com suas implicações na atividade diária dos motoristas, torna-se fator de constante descontentamento. Pistas mal conservadas, engarrafamentos, pontos de embarque e desembarque mal localizados, outros veículos e aspectos normativos do trânsito, somados a variáveis ergonômicos do posto de trabalho, configuram-se como essências da penosidade do trabalho de motorista. Se for considerado que este é o local diário de trabalho, é possível inferir um nível alto de desgaste tanto físico quanto mental, do motorista. Os fatores ergonômicos configuram-se centrais na discussão da qualidade do serviço prestado e das condições do ambiente de trabalho dos motoristas. O ruído no posto de trabalho, por exemplo, está diretamente relacionado à posição do motor.

Estar constantemente sob vigilância, seja de fiscais ou dos próprios passageiros, é uma forma de pressão psicológica, visto que, durante a maior parte de sua jornada de trabalho, os motoristas não trocam sequer uma palavra com outra pessoa, com receio de criar situações que possam comprometer a sua avaliação na empresa. 
O motorista de ônibus divide o espaço interno de trabalho com o cobrador, mas nem por isso pode-se dizer que não trabalha só. É o único responsável pelo cumprimento da tarefa de transportar pessoas, suas decisões têm que ser tomadas visando preservar a integridade física dos passageiros além da sua própria e a manutenção do equipamento (ônibus), restando-lhe, ainda, o ônus do desgaste mental. Os engarrafamentos se traduzem em maior tempo para cumprir os percursos, onerando os serviços de transporte, pois as empresas precisam dispor de um número maior de ônibus, para um uso restrito a algumas horas do dia, o que afeta o valor das tarifas, atingindo também o bolso do consumidor, nesse caso, o passageiro.

É por meio da caracterização das reais condições de trabalho dos motoristas que se pode vislumbrar soluções possíveis para o transporte público urbano. É preciso implementar políticas públicas que visem ao bem-estar não só do profissional que trabalha com o transporte coletivo, mas também dos passageiros, possibilitando o aumento do número de usuários. A opção pelo transporte público, por sua vez, diminui o número de veículos nas vias públicas, aumenta a arrecadação das empresas e do município e possibilita que parte desses recursos seja revertida em programas para o melhoramento do trânsito. Acredita-se que programas de educação para o trânsito podem configurar-se em alternativas de abordagem do problema, incluindo nesses programas tanto os motoristas profissionais quanto os demais motoristas. O objetivo é viabilizar o melhoramento da interação dos diferentes componentes do meio viário, sejam eles motoristas, pedestres ou motociclistas, sejam as formas de sinalizações e sua eficácia em transmitir a informação desejada.

Quanto ao desgaste físico, que acaba por influenciar nos níveis de fadiga e estresse, a educação pode ser voltada a aspectos específicos da profissão de motorista, como o fato de trabalhar sentado e forçar constantemente os membros inferiores (na aceleração e frenagem). Programas educacionais e de conscientização que levem até esse profissional o ensino de técnicas de alongamento e auto-correção postural, por exemplo, podem tornar-se alternativas que possibilitem a redução de danos ao sistema músculo-esquelético, possibilitando ao motorista realizar essas técnicas durante sua jornada diária de trabalho.

Paralelamente, estudos realizados de forma interdisciplinar, que levem em consideração as necessidades de conforto físico e psíquico dos motoristas, bem como as possibilidades técnicas de implementação, podem auxiliar no redesenho das cabines e do posto de trabalho do motorista, tornando seu ambiente de trabalho mais adequado. Juntos, programas educacionais para o bem-estar físico e mental, bem como uma reorganização ergonômica do local de trabalho do motorista, podem tornar-se importantes fatores de dimensionamento de sua qualidade de vida no trabalho.

\section{Referências}

Belkie, K., \& Schall, P. (1998). On a San Francisco public transportation line: burden and consequences upon the human operator. In K. Belkie \& P. Schall (Org.), San Francisco bus drivers study (pp. 20-45). San Francisco: San Francisco Municipal Railway/Transport Workers Union/The City of San Francisco.

Cavalcanti, V. L. (1996). Subsídios técnicos que justifiquem a manutenção da aposentadoria especial para motoristas de ônibus urbanos. Manuscrito não-publicado, São Paulo.

Comissão de Saúde Pública da Espanha. (2000). Protocolos de vigilância sanitária específica: ruído. Madri: Autor.

Cooper, C., \& Marshall, J. (1976). Occupational sources of stress. A review of the literature relating to coronary heart disease and mental ill health. Journal of Occupational Health Psychology, 49, 11-28.

Cordeiro, E., Lima-Filho, E. C., \& Nascimento, L. C. R. (1994). Associação da perda auditiva induzida pelo ruído com o tempo acumulado de trabalho acumulado entre motoristas e cobradores. Cadernos de Saúde Pública, 10(2), 210-221.

Costa, L. B., Koyama, M. A. H., Minuci, E. G., \& Fischer, F. M. (2003). Morbidade declarada e condições de trabalho: o caso dos motoristas de São Paulo e Belo Horizonte. São Paulo em Perspectiva, 17(2), 54-67.

Cruz, R. M., Alchieri, J. A., \& Sardá, J. J. (Orgs.). (2002). Avaliação e medidas psicológicas. São Paulo: Casa do Psicólogo.

Cruz, R. M. (2001). Psicodiagnóstico de síndromes dolorosas crônicas relacionadas ao trabalho. Tese de doutorado não-publicada, Universidade Federal de Santa Catarina, Florianópolis.

Dejours, C. (1992). A loucura do trabalho: estudo de psicopatologia do trabalho ( $5^{\mathrm{a}}$ ed.). São Paulo: Cortez \& Oboré.

DETRAN - Departamento Regional de Trânsito (s/d). Condições adversas do motorista. Acessado em 07 de janeiro de 2007, em: http:// www.detran.pe.gov.br/condicoes_adv_motorista.shtml.

Ferreira, M. R., \& Pinto, R. B. (1998). A contribuição da Psicologia Ambiental para o estudo das situações de trabalho. Relatório de pesquisa não-publicado, Universidade Federal de Santa Catarina, Florianópolis.

Frankenhaueuser, M. (2001). La carga de trabajo in factores psicossociales y de organización. Enciclopedia de salud y seguridad en el trabajo. Acessado em 16 de outubro de 2000, em: http://www.mtas.es/insht/EncOIT/Index.htm.

Griffin, M. J. (2001). Vibraciones. Enciclopedia de salud y seguridad en el trabajo. Acessado em 16 de outubro de 2000, em: http://www.mtas.es/ insht/EncOIT/Index.htm.

Hoffmann, M. H. (2000). Áreas de intervenção da Psicologia do Trânsito. Revista Alcance-CCS, UNIVALI, ano VII, 2, 26-36.

Luna, S. V. (1998). Planejamento de pesquisa: uma introdução. São Paulo: EDUC.

Millies, B. A. (2001). Conducción de camiones y autobuses. Enciclopedia de salud y seguridad en el trabajo. Acessado em 16 de outubro de 2000, em: http://www.mtas.es/insht/EncOIT/Index.htm.

Netterstrom B. et al. (1988). Traditional coronary risk factors in bus drivers. Ugeskr Laeger, 150(25), 1542-1545.

Netterstrom B., \& Juel K. (1988). Impact of work-related and psychosocial factors on the development of isquemic heart disease among urban bus drivers in Denmark. Scandinavian Journal of Work Environmental Health, 14(4), 231-238.

Nielsen, B. (2001). Efectos del estrés por calor y trabajo en ambientes calurosos. Enciclopedia de salud y seguridad en el trabajo. Acessado em 16 de outubro de 2000, em: http://www.mtas.es/insht/EncOIT/Index.htm. 
NTU - Associação Nacional das Empresas de Transportes Urbanos. (1999). Transporte público urbano: crise e oportunidades. Acessado em 16 de outubro de 2000, em: www.ntu.org.br/publicacoes/publicacoes.

Paes-Machado, E., \& Levenstein, C. (2002). Assaltantes a bordo: violência, insegurança e saúde no trabalho em transporte coletivo de Salvador, Bahia, Brasil. Cadernos de Saúde Pública, 18(5), 1215-1227.

Sato, L. (1995). A representação social do trabalho penoso. In M. J. Spink (Org.), O conhecimento do cotidiano: as representações sociais na perspectiva da Psicologia Social (pp. 188-211). São Paulo: Brasiliense.

Selligmann-Silva, E. (1995). Psicopatologia e psicodinâmica no trabalho. In R. Mendes (Org.), Patologia do trabalho (pp. 287-310). Rio de Janeiro: Atheneu.

Silva, L. R., \& Mendes, R. (2005). Exposição combinada entre ruído e vibração e seus efeitos sobre a audição de trabalhadores. Revista de Saúde Pública, 39(1), 9-17.

Smith, M. J. (1987). Occupational stress. In Salvendy, G. (Org.), Handbook of human factors. Nova York: Wiley.

Stokols, D. (2001). El diseño del entorno in factores psicossociales y de organización. Enciclopedia de salud y seguridad en el trabajo. Acessado em 16 de outubro de 2000, em: http://www.mtas.es/insht/EncOIT/Index.htm.
Stokols, D., \& Altman, I. (1987). Handbook of environmental psychology, 2 vols. Nova York: Willey.

Sundstrom, E., Bell, P. A., Busby, P. L., \& Asmus, C. (1996) Environmental Psychology: 1989-1994. Annual Review of Psychology, 47, 485-513.

Suter, A. H. (2001). Naturaleza y efectos del ruido. Enciclopedia de salud y seguridad en el trabajo. Acessado em 16 de outubro de 2000, em: http:// www.mtas.es/insht/EncOIT/Index.htm.

Tapia-Granados, J. A. (1998). Reducing automobile traffic: an urgent policy for health promotion. Revista Panamericana de Salud Publica, 4, 227-241.

Winkleby, M. A., Ragland, D. R., Fisher, J. M., \& Syme, S. L. (1988). Excess risk of sickness and disease in bus drivers: a review and synthesis of epidemiologic studies. International Journal of Epidemiology, 17(2), 255-262.

Wisner, A. (1987). Por dentro do trabalho - ergonomia: métodos e técnicas. São Paulo: FTD/Oboré.

Zanelli, J. C. (1992). Um procedimento informatizado de entrevistas recorrentes para identificação e análise de problemas organizacionais e sociais. In Anais XVI Enanpad (pp. 01-15). Canela: ANPAD.

${ }^{1}$ Os terminais observados referem-se aos existentes em Florianópolis no ano de 2002. Atualmente está em vigência outro sistema que integra uma série de novos terminais.

Márcia Battiston, mestre em Psicologia pela Universidade Federal de Santa Catarina, é professora no Curso de Psicologia do Centro Universitário Barriga Verde (SC). Endereço para correspondência: Rua Felipe Schmidt, 515, Sala 909, Ed. Pórtico (Centro); Florianópolis, SC; CEP 88010-001. Tel.: (48) 3025-5022 / 9917-1615. Fax: (48) 3028-9345. E-mail: mabattiston@yahoo.com.br

Roberto Moraes Cruz, doutor em Engenharia de Produção pela Universidade Federal de Santa Catarina, é professor no Curso de Psicologia e no Programa de Pós-Graduação em Psicologia da Universidade Federal de Santa Catarina.

Maria Helena Hoffmann, doutora em Psicologia pela Universidad de Valencia (Espanha), é professora no Curso de Psicologia da Universidade do Vale do Itajaí e psicóloga da Secretaria de Estado da Segurança Pública (SC). 